\title{
MODELLING ASSISTED INJECTION MOLDING WITH MAGNETIC Field For COMPLEX Polymeric Products
}

\author{
Opran Constantin Gheorghe, Balota Doru Andrei, Teodorescu Draghicescu Florin, \\ Dobrescu Tiberiu Gabriel
}

\author{
Production Engineering Department, Politehnica University of Bucharest, \\ Splaiul Independenţei No. 313, 060042 Bucharest
}

\begin{abstract}
This paper presents the modeling and the dynamic control of the complex integrated technological system of a polymeric product - injection mold, at the injection molding assisted by electromagnetic induction (IM-IE) for the monitoring of the temperature cycle technology at the functional areas of the product in order to achieve a consistent quality. As a result of the research conducted for this case, the paper presents the optimization of the injection process for the product using the finite element analysis. For the temperature cycle monitoring it was adopted the variotherm heating system through electromagnetic induction to the injection process that uses alternately heating environment electromagnetic induction system and respectively cooling environment water. Through research conducted result the optimizing technology and quality products comply with the dimensional conditions and the improved surface quality.
\end{abstract}

Keyword: injection moulding; modelling, magnetic field; polymeric products; quality products
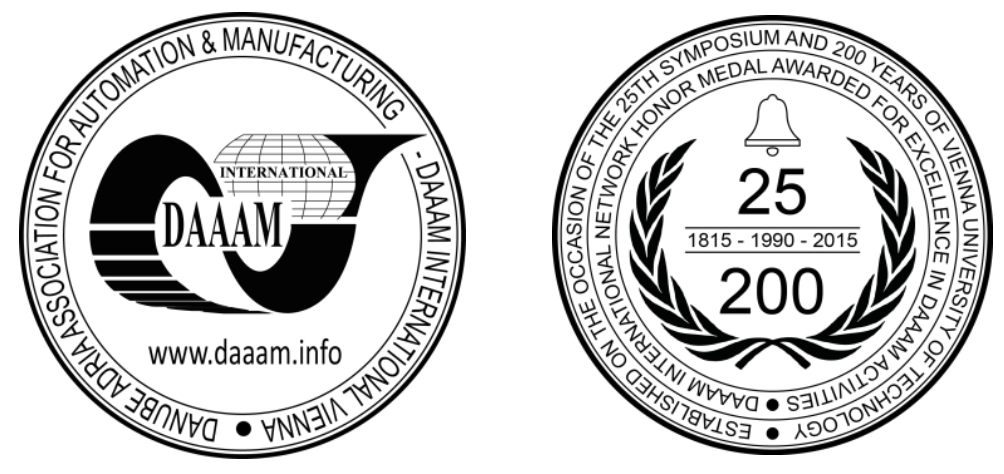

This Publication has to be referred as: Opran, C[onstantin]; Balota, D[oru] A[ndrei]; Teodorescu, D[raghicescu] F[lorin] \& Dobrescu, T[iberiu] G[abriel] (2016). Modelling Assisted Injection Molding with Magnetic Field for Complex Polymeric Products, Proceedings of the 26th DAAAM International Symposium, pp.0301-0310, B. Katalinic (Ed.), Published by DAAAM International, ISBN 978-3-902734-07-5, ISSN 1726-9679, Vienna, Austria DOI:10.2507/26th.daaam.proceedings.041 


\section{Introduction}

Injection molding parts with thin walls creates new challenges in every aspect of the injection process, including a requirement for high speed injection machines, design of products and molds, material selection and process control. To ensure high quality complex parts is necessary to provide the dynamic control of the temperature. The injection temperature control using the induction heating is shown in Figure 1:

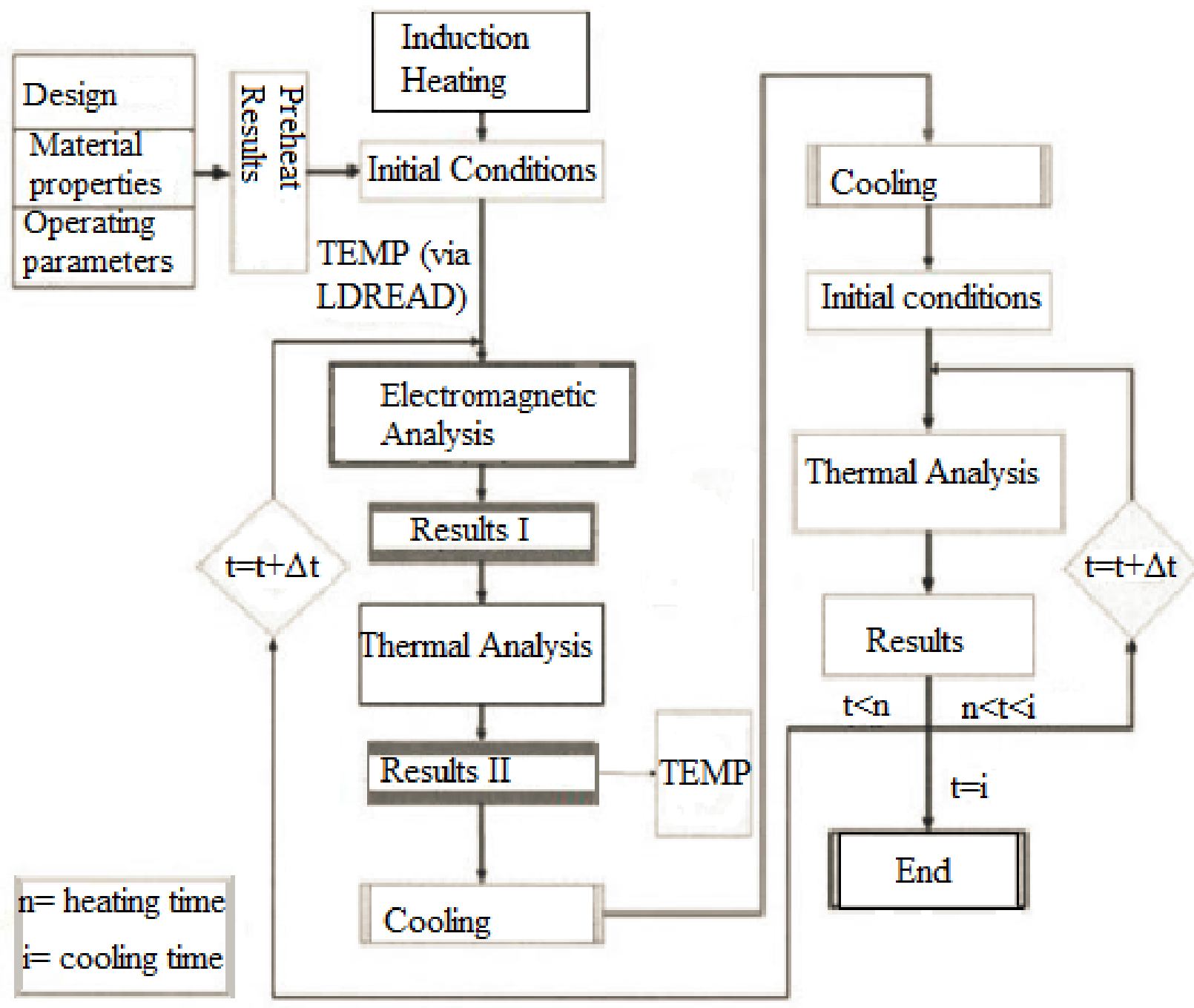

Fig. 1. Diagram of the thermal electromagnetic couple (heating and cooling)

In the present study, it is intended the dynamically control the mold temperature using electromagnetic induction. This is because the temperature is probably one of the most important parameters in polymer processing. This measurement is very difficult. Satisfactory results can be obtained only through the mold temperature control if the performance temperature control unit is suitable for quantities of heat to be exchanged in the mold. This paper presents the advantages of a less conventional heating techniques using electromagnetic induction. The operating principle of electromagnetic induction currents induced interaction between a ferromagnetic metal fitting two or more alternative magnetic fluxes created these currents. Since the fundamental principle of this device is electromagnetic induction, induction tools can operate only in AC, or, in general, only on a variable. Theoretical calculation of electromagnetic induction is based on the classical theory of electromagnetism. This approach requires a brief but systematic problem of this important basic physical theory. According to Maxwell's equations is known based on Coulomb's law to obtain the intensity of the electrostatic field produced by a Q-off load located in an isotropic medium expression is [1]:

$$
\bar{E}_{M}=\frac{Q}{\kappa_{e} \varepsilon r^{3}} \cdot \bar{r}
$$

where $\kappa_{e}=4 \pi$ in scale streamlined systems and physical units SI, $\varepsilon$ is the coefficient (electric) rationality and $\bar{r}$ is the radius vector of the observation point $\mathrm{M}$. In anisotropic media, the expression of the same physical quantities 
becomes:

$\bar{E}_{M}=\frac{Q}{\kappa_{e} r^{3}} \cdot \overline{\bar{\varepsilon}}-1 \cdot \bar{r}$

where

$\overline{\bar{\varepsilon}}=\left|\begin{array}{ccc}\varepsilon_{x x} & \varepsilon_{x y} & \varepsilon_{x z} \\ \varepsilon_{y x} & \varepsilon_{y y} & \varepsilon_{y z} \\ \varepsilon_{z x} & \varepsilon_{z y} & \varepsilon_{z z}\end{array}\right|$

is the tensor of dielectric constant (permittivity). By analogy with electrostatics equations (integral and local), the Maxwell's equations are [1]:

$$
\Phi_{\bar{B}, \Sigma}=\kappa_{i} Q_{m g, \text { int } . \Sigma} \text { and } \nabla \bar{B}=\kappa_{i} \rho_{Q m g}
$$

where $Q_{m g \text {,int. } \Sigma}$ is the magnetic charge enclosed the $\Sigma$ area. Electromagnetic phenomena don't require introducing a magnetic load. Therefore we believe that $Q_{m g}=0$ and $\rho_{Q m g}=0$ and therefore the final and full expression respectively the local Maxwell equation will be:

$$
\Phi_{\bar{B}, \Sigma}=0, \nabla \bar{B}=0
$$

To determine the current density expression (Maxwell) of "movement" (due the variation vector $\bar{D}$ - the electric displacement) they are considered a plate area A (electrically charged surface density $\sigma$ ) - a capacitor. Since the $\mathrm{x}$ component of electric flux between the plates is:

$$
D_{x}=\kappa_{i} \sigma
$$

It is obtained the expression of the (surface) density current "movement":

$$
j_{d x}=\frac{1}{A} \cdot \frac{d Q}{d t}=\frac{1}{A} \cdot \frac{d}{d t}(A \cdot \sigma)=\frac{1}{\kappa_{i}} \cdot \frac{d D_{x}}{d t}
$$

Relations (6) and (7) lead to the local expression of (differential) Maxwell-Biot-Savart-Ampere equation:

$$
\operatorname{rot} \bar{H}=\kappa_{i}\left(\bar{j}_{c}+\frac{1}{\kappa_{i}} \cdot \frac{d \bar{D}}{d t}\right)=\kappa_{i} j_{c}+\frac{d \bar{D}}{d t}=\kappa_{i} j_{c}+\frac{\partial \bar{D}}{\partial t}
$$

where $\bar{j}_{c}$ is the conduction current density (due to free movement of electric charge carriers). So for bodies at rest ( $\bar{v}=0)$ :

$$
\frac{d \bar{D}}{d t}=\frac{\partial \bar{D}}{\partial t}+\frac{\partial \bar{D}}{\partial x} \cdot \frac{d x}{d t}+\frac{\partial \bar{D}}{\partial y} \cdot \frac{d y}{d t}+\frac{\partial \bar{D}}{\partial z} \cdot \frac{d z}{d t}=\frac{\partial \bar{D}}{\partial t}+(\bar{v} \cdot \nabla) \bar{D}=\frac{\partial \bar{D}}{\partial t}
$$

The phenomenon of electromagnetic induction and electromagnetic essential that the phenomenon is described by Faraday's law: 
$e_{C}=-\frac{d \Phi}{d t}$

where $e_{C}$ is the tension (force) induced in the electric conductor $\mathrm{C}$ and $\Phi, \bar{B}, C$ the magnetic flow (magnetic induction) trough the inner surface of the conductor $\mathrm{C}$. The differential electric potential is equal to the work done over the elementary electric charge unit, where

$$
d V=\frac{d L}{q}=\frac{\bar{F} \cdot d \bar{r}}{q}=\bar{E} \cdot d \bar{r}
$$

Finally, it is found that the electric voltage is equal to the movement of electric field strength over the enclosed conductor C:

$$
e_{C}=\oint_{C} \bar{E} \cdot d \bar{r}
$$

Because - for bodies at rest - it is possible to reverse the order of operators $\frac{d}{d t}$ and $\int_{\Sigma}$ to obtain the full expression of Maxwell-Faraday equation:

$$
e_{C}=\oint_{C} \bar{E} \cdot d \bar{r}=\Gamma_{\bar{E}, C}=-\frac{d}{d t} \int_{\Sigma} \bar{B} \cdot d \bar{A}=-\int_{\Sigma} \frac{\partial \bar{B}}{\partial t} \cdot d \bar{A}=-\Phi_{\frac{\partial \bar{B}}{\partial t}, \Sigma}
$$

where $\Sigma$ is the area surrounding the C conductor (fig. 2) [1]

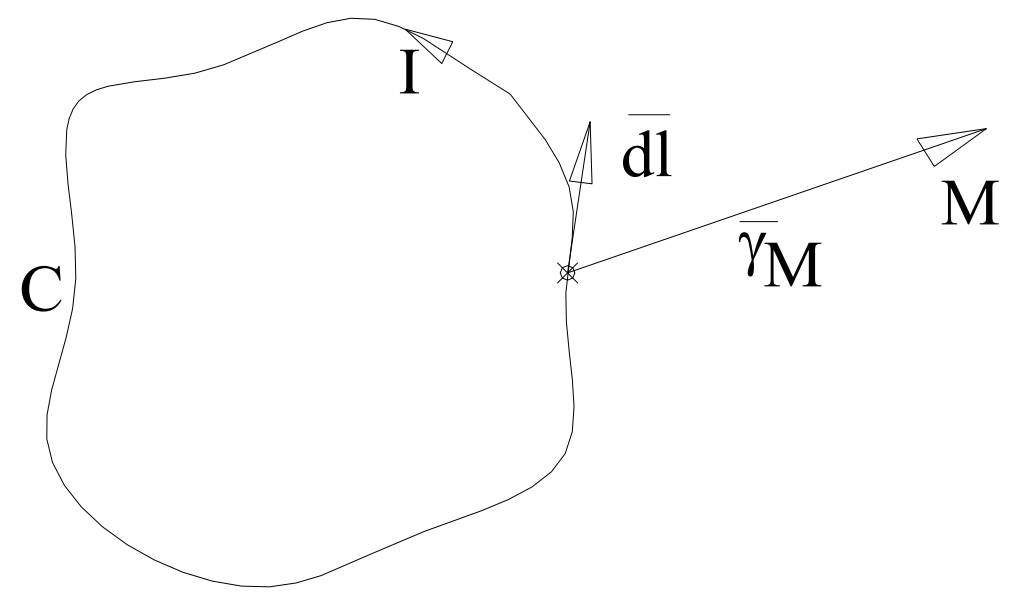

Fig. 2. The area surrounding the C Conductor [1]

\section{Optimize the injection process using the finite element analysis}

This paper presents the results of researches on issues relating to injection molding process optimization and also to bring to light new techniques used to achieve qualitative growth products. To establish process conditions and properties is necessary to use the finite element analysis method.

Finite element analysis requires more precise definition of material properties to generate predictions closer to reality. The properties used to characterize the Moldflow software product using the Moldflow 2012, the conditions imposed by the process (mold temperature, melt temperature, the temperature of removal from the mold, the maximum shear tension, the maximum degree of shear) rheological properties, thermal properties material and mechanical properties of the material used. [21] 
Optimizing conditions for obtaining the product, such as mold temperature, melt temperature and time of injection material are the best starting points for an analysis of finite element material flow. [22] In order to carry out optimization analysis of the product is necessary to set the input parameters, these being: the discretized, location of injection points, material selection process and other settings. Product model discretized in this case, a ABS navigation system housing is shown in Figure 3 and 4 where the product is shown meshing elements studied with dual side global domain size of $2 \mathrm{~mm}$. [2,3,4,5,6,7, 20]
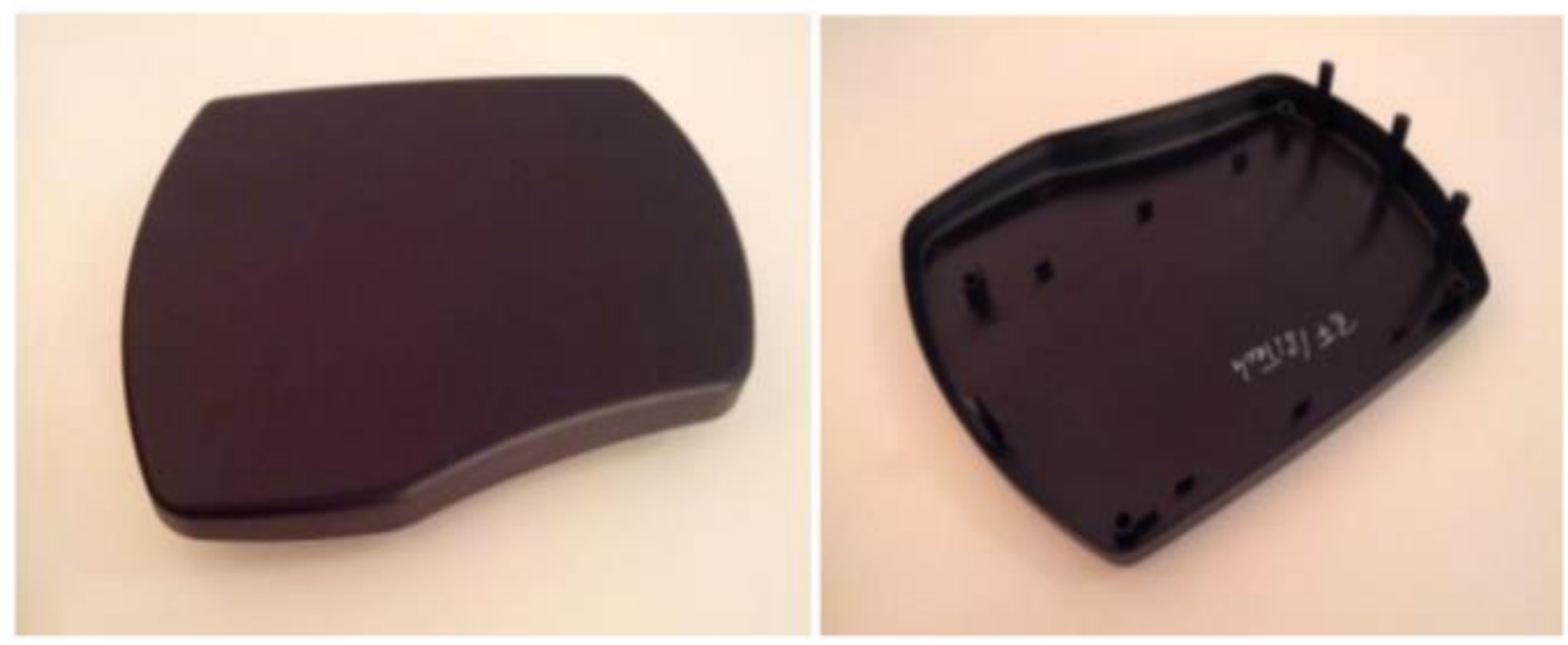

Fig. 3. Navigation housing system made in ABS [20]

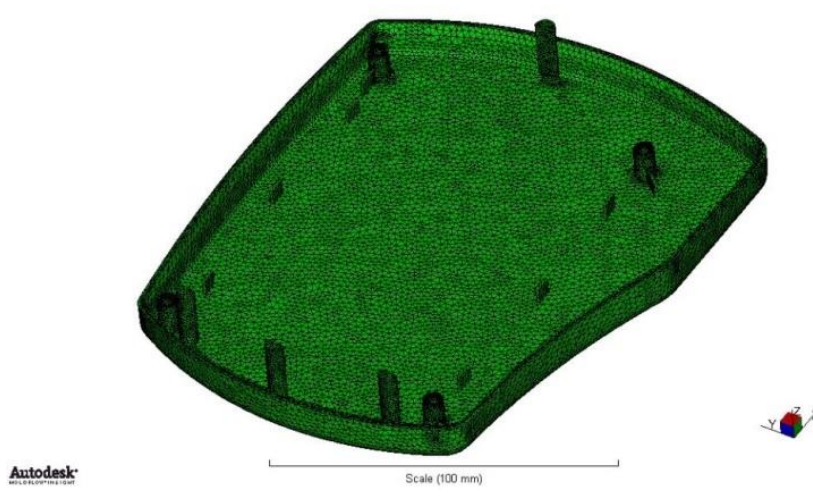

Fig. 4. The product meshing [20]

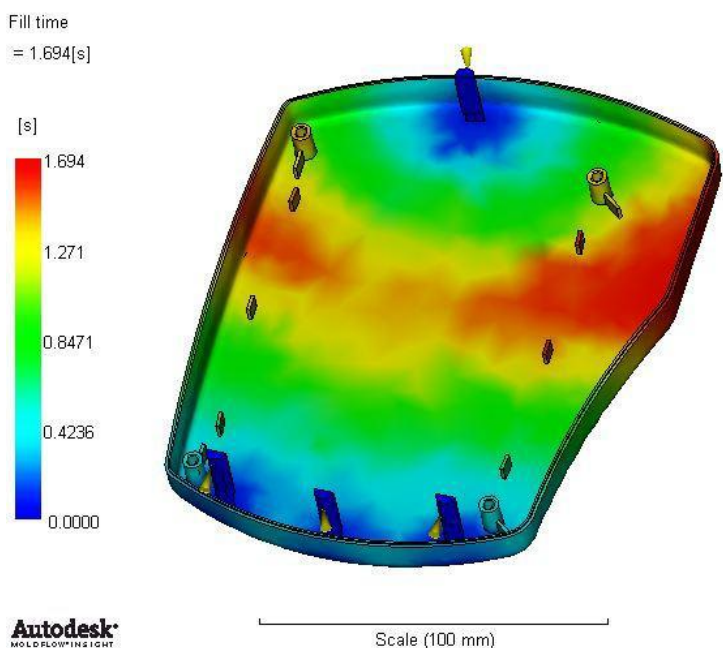

Fig. 5. The filling process of the mold [20]

The Properties results allow us to change how they may be viewed as helping us to interpret them. The paper analyzed and interpreted results concerning: a) the time of the mold filling; b) flow front temperature c) temperature along the flow path. Its results indicate progression while material flow. From Figure 5 it can be seen during the filling of the mold nest which in this case has a value of 1.694 seconds, and the outline of the product showing a good filing is uniform.

\subsection{The temperature of the flow front obtained with Autodesk Moldfow Insight}

The temperature of the flow front is the temperature at which the molten polymeric material fills the mold nest. The temperature at the inside of the material and does not involve large movements, a phenomenon that can be observed in Figure 5 (the values of the temperature ranges from $249.2^{\circ} \mathrm{C}$ to $252.3^{\circ} \mathrm{C}$ ). $[8,9,10,20]$ 


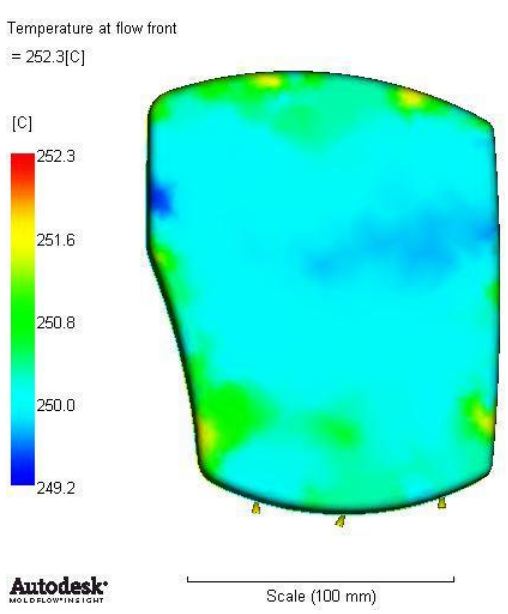

Fig. 6. The flow front temperature [8]

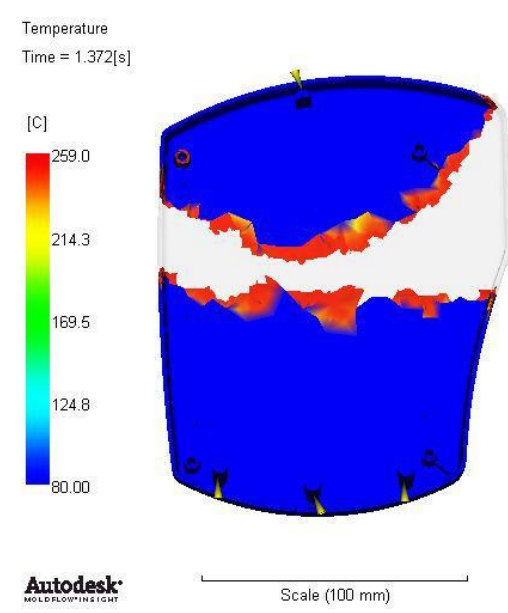

Fig. 7. The temperature throughout the cross-section [8]

\subsection{The Temperature along the section}

With the graph shown in Figure 6 and 7 can be seen the temperature at any point along the section and time along section. Generally the temperature of the section does not exceed the absolute maximum temperature data which is based on material. $[8,11,12,13,20]$

\section{Monitoring of the temperature cycle using the variotherm electromagnetic induction system}

Since low and constant temperature of the mold is restricted during cooling, conventional injection molding process cannot keep up with market demands. Recently adopted is a new strategy that uses a dynamic temperature applied to the injection mold. This new technology of injection molding is the variotherm injection. The injection process the mold surface is heated to the required temperature prior to injecting material. Throughout the filling phase, the mold temperature is maintained at that value in order to facilitate the flow of polymeric material. Then the product is cooled rapidly and the course of the extraction phase from the mold. Housing track navigation system uses a variotherm process of injection molding. We use electromagnetic induction as method of heating the mold and as a method of cooling we use water. Of the injection parameters, the injection temperature is not critical area. Raising the temperature of the mold surface area, the quality of the product will be improved and the cooling time is increased. The goal is to heat the mold surface and maintain a reasonable time of the injection cycle. This facilitates flow of the material and also to give more smooth surfaces. During the compression and cooling phases, the mold is subjected to a much lower temperature in order to plasticise the material, and the cycle time to obtain the lowest. The experiments were set manually varying temperatures it is subjected to mold as you can see in Figure 8, the number of iterations used for the study is 10 . [8, 14,15, 20]

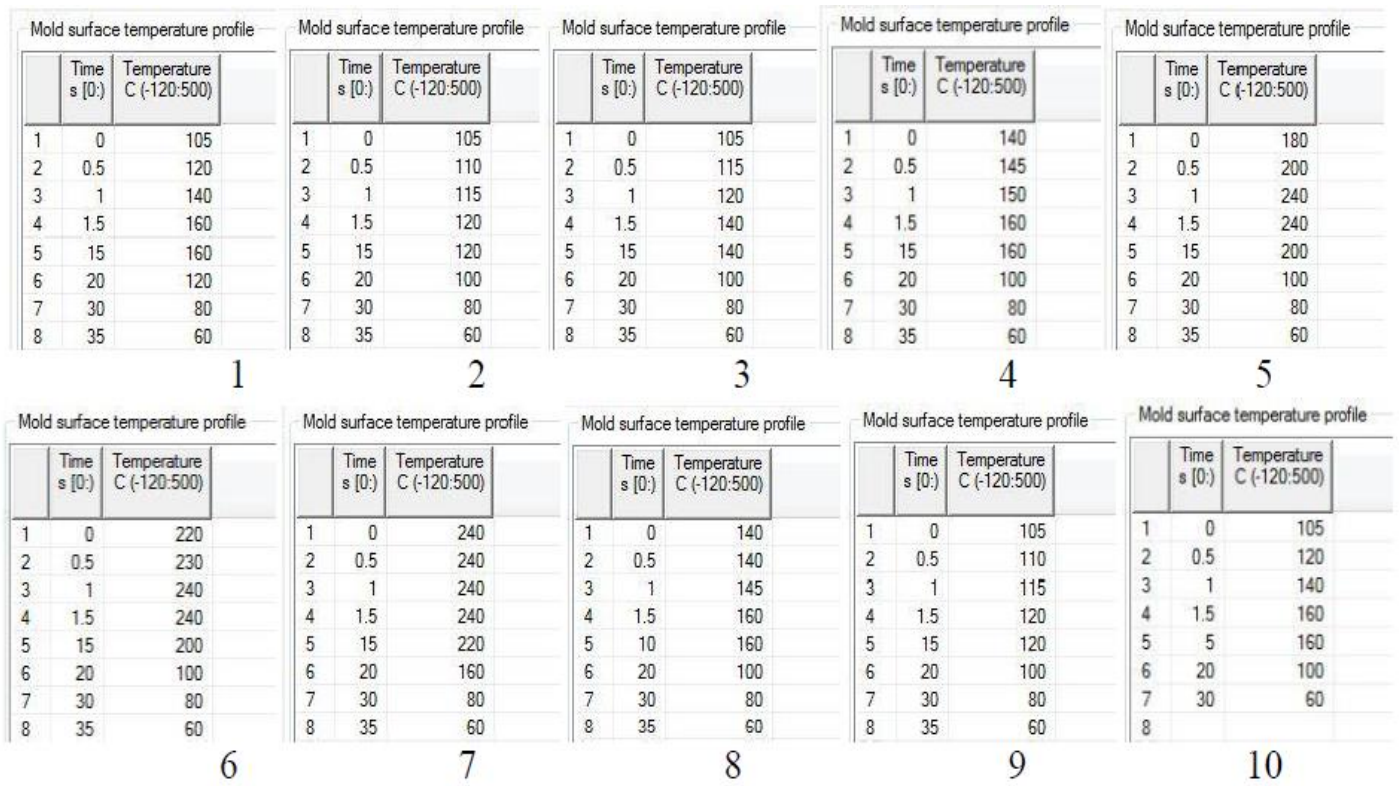

Fig. 8. Mold temperature values [20] 
In the pages following is chosen the version number 4. According to Figure 9 filling time decreased from classical model from 1.694 seconds to 1.671 seconds. This is due to the good flow properties of the material when subjected to elevated temperatures. [16,17, 20]

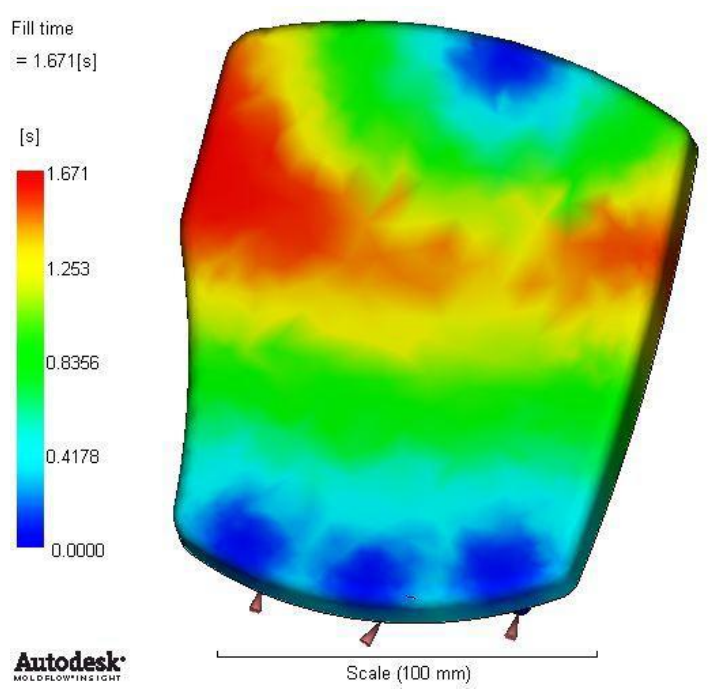

Fig. 9. filling of the mold [20]

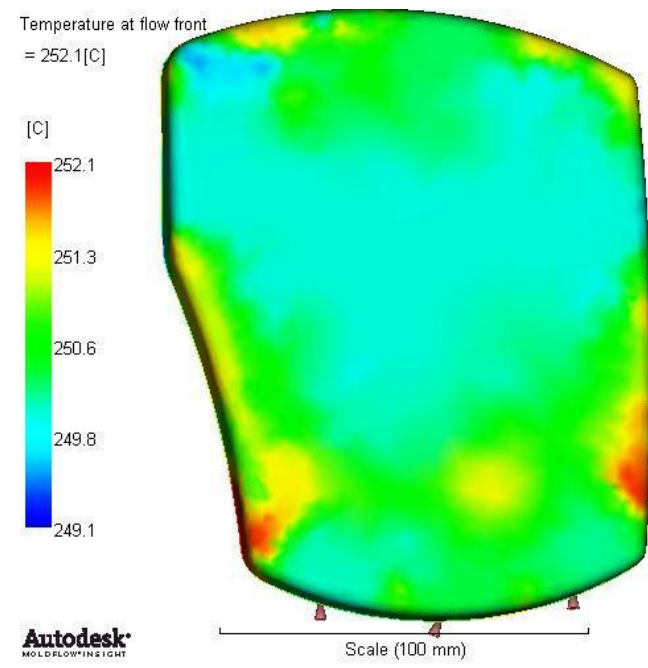

Fig. 10. the front melt temperature [20]

There is a slight change in the temperature values of the melt front. In the conventional front fusing temperature has values between $249.2^{\circ} \mathrm{C}$ and $252.3^{\circ} \mathrm{C}$, and values obtained by raising the mold temperature is from $249.1^{\circ} \mathrm{C}$ to $252.1^{\circ} \mathrm{C}$. As can be seen in Figure 10 the die is not applied to various temperatures considerably higher temperature influence held by the flow front of the molten material. Figure 11 depicts the change in pressure inside the mold [18]. Corresponding to the injection cycle may be observed following steps: start of injection (time it is not yet filled nest), the increase in pressure and filling of the cavity, further increase of the pressure to reach its maximum value, maintaining the pressure constant during the solidification of the material decreasing the pressure to solidify the plastic and the plastic material. [19, 20, 21, 22].

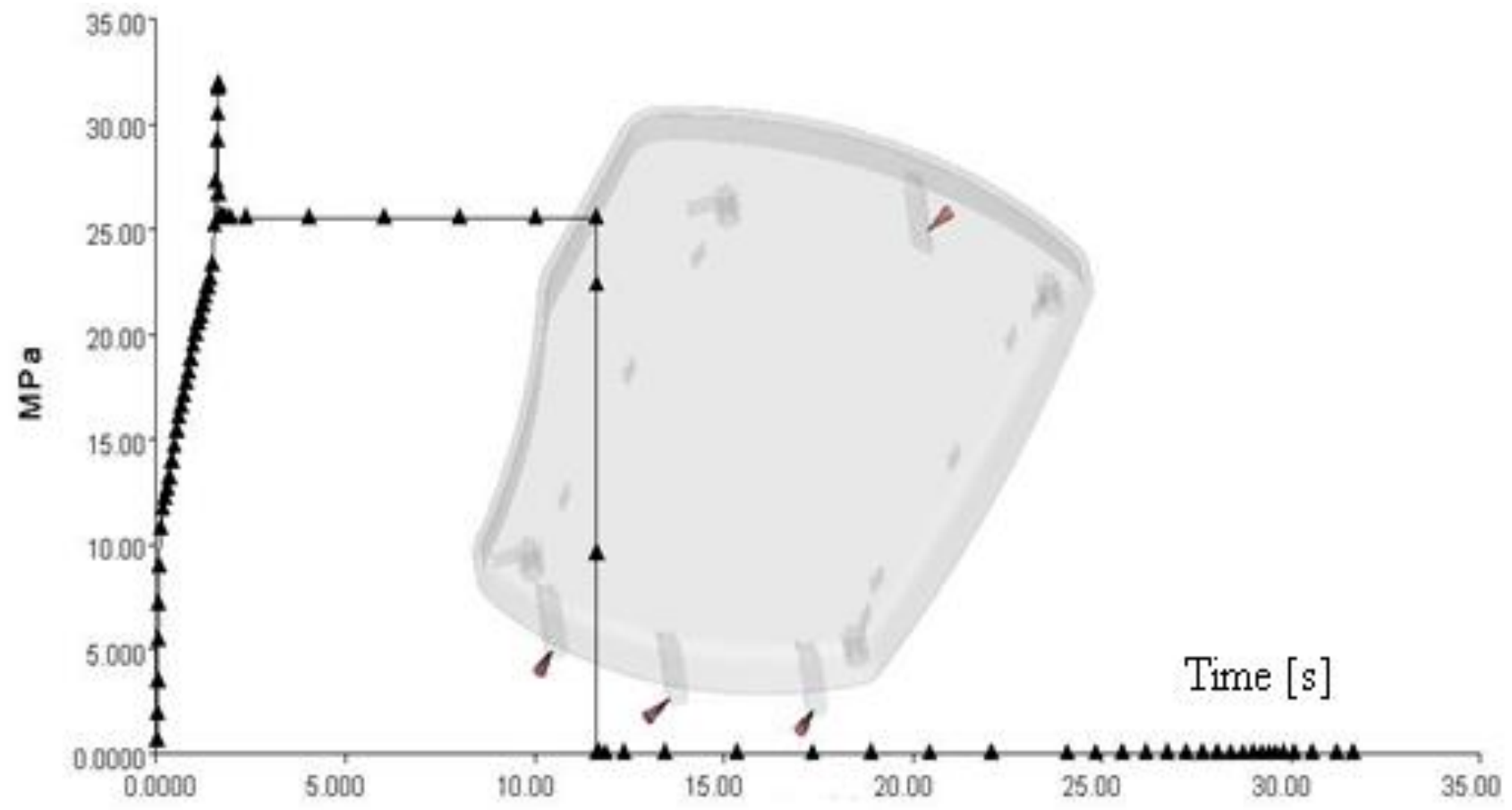

Fig. 11. The pressure in the mold [20] 
In Figure 12 we have shown the temperature range for the injection process under study depending from the time.

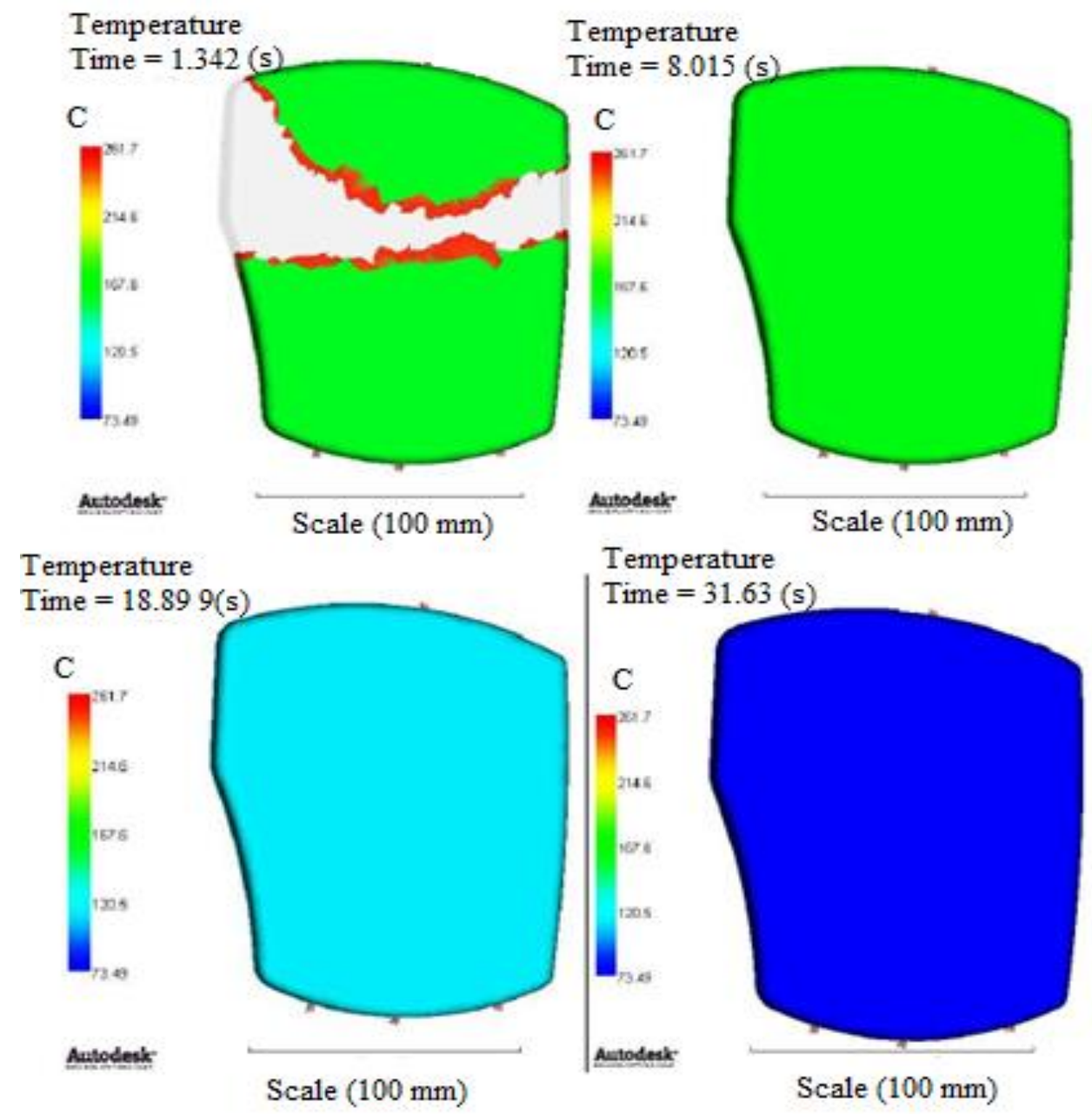

Fig. 12. The temperature depending from the time [20]

Following variotherme temperature conditions we managed to largely eliminate weld lines on the external surface of the product as can be seen in Figure 13. On the left are shown the weld lines to the classic injection and on the right we presented seams after optimization. [20]

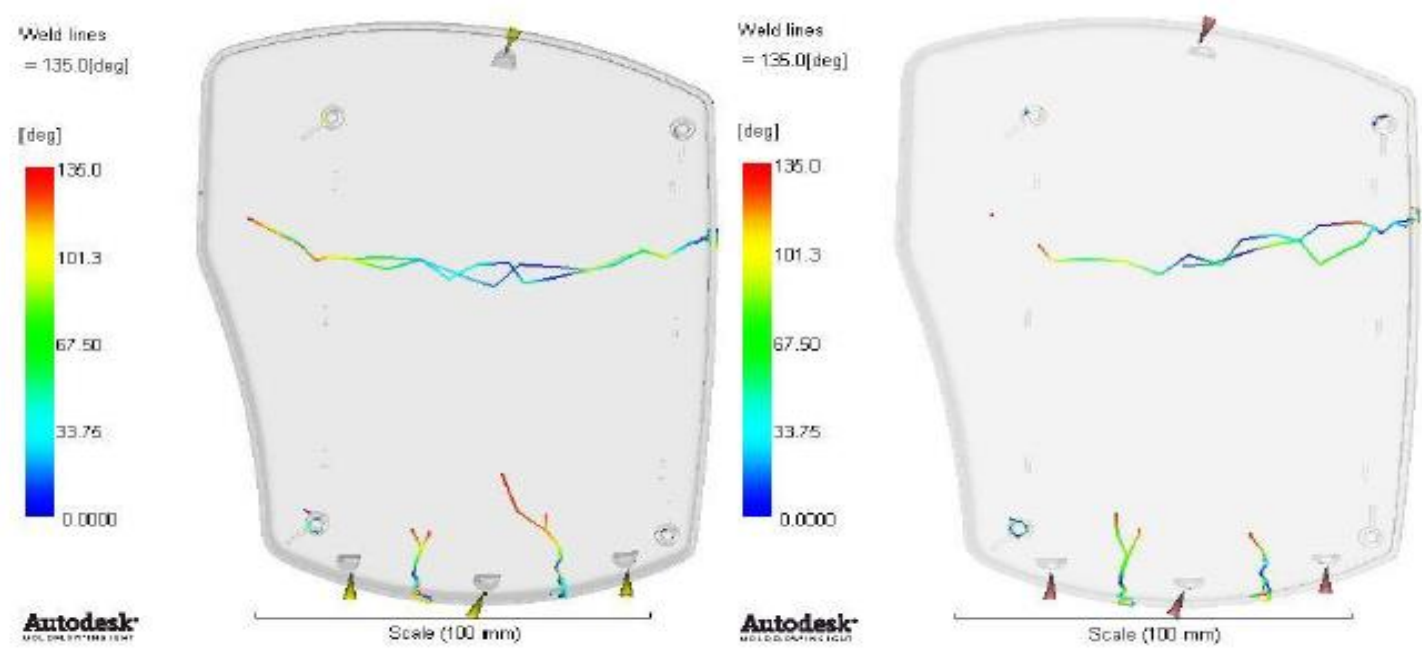

Fig. 13. Welds lines [20] 


\section{Conclusions}

The problem was to find a method to monitoring the temperature of a specific polymeric product during injection molding. This problem was solved by the development of the embedded system who measure the variable temperature during injection moulding.

The results of the research on heating at injection moulding were presented as graphs that relate to other parameters such as the structure of the mould and the material injected respectively their temperatures and pressures during the process. These graphs have been set in order to improve the efficiency of the heating and cooling phase. Validation of the experimental results demonstrate the superior efficiency of the system again variotherm to electromagnetic induction heating. Macroscopic observation of defective products surface type welding line showed an improvement in quality. As a result of simulations was obtained by reducing surface weld lines

The future plans are focused on the optimisation of the temperature measure for complex moulded injection parts.

\section{References}

[1] Iordache D.A.; 2010;Elements of the classical theory of electromagnetism, Eureka Magazine, 20(237-238) pp. 5461.

[2] Autodesk, 2012;Learning Autodesk Moldflow Insight Basic - Theory and Concepts. Autodesk Inc. 111 Mclnnis Parkway San Rafael, USA.

[3] Alfredo E., 2006; The complete part design handbook for injection molding of thermoplastics, Hanser Publishers, Munich.

[4] Arburg M.R.; 2004; Practical Guide to Injection Moulding, Rapra Technology Limited. UK.

[5] Baehr H.D.; Tephan K.; 2006; Heat and Mass Transfer, second edition; Springer, New York, pp. 628-639.

[6] BALÁZS Illés, 2010; Distribution of the heat transfer coefficient in convection reflow oven, Appl. Therm. Eng. 30, pp. 1523-1530.

[7] Akiyoshi, H.; Hiraki, E.; Tanaka, T.; Okamoto, M.; Matsuo, T.; Ochi, K., 2014; Peak Power Shaving of an Electric Injection Molding Machine With Supercapacitors; IEEE TRANSACTIONS ON INDUSTRY APPLICATIONS, vol.50, no.2, pp.1114-1120, ISSN 0093-9994.

[8] Balotă Doru Andrei, Pătraşcu Alexandru, Opran Constantin, 2010; Monitoring of Temperature Field in the Injection Mould Heated by Electromagnetic Induction, Proceedings CNC Technologies Fourth Edition, Politehnica Press, București, 5-7 Mai 2010.

[9] Balotă Doru Andrei, Vlase Aurelian, Pătraşcu Alexandru, Gheorghe Tudor Vlad, 2011; Research on the optimization of injection molding process using numerical simulations, ModTech International Conference-New Face of TMCR, Modern Technologies, Quality and Innovation, , Vadul lui Vodă-Chișinău, Republic of Moldova, 25-27 Mai 2011.

[10] Chang P.C.; Hwang S.J.; 2006; Experimental investigation of infrared rapid surface heating for injection molding, Journal of Applied Polymer Science, 102(4), pp. 3704-3713.

[11] Chen S.C.; Chang Y.; 2009; Effect of cavity surface coating on mold temperature variation and the quality of injection molded parts, International Communications in Heat and Mass Transfer, 36 (10), pp. 1030-1035.

[12] Chen S.C.; Chien R.D.; 2009; Feasibility evaluation of gas assisted heating for mold surface temperature control during injection molding process, International Communications in Heat and Mass Transfer 36 (8), pp. 806-812.

[13] Marin, D.; Raicu, L. \& Petrescu; 2012; L.C.M.: Cylindric Shape - a Design Creative Resource; Annals of DAAAM for 2012 Proceedings of the 23rd International DAAAM Symposium, ISBN 978-3-901509-91-9, pp 0179-0182, Published by DAAAM International, Vienna, Austria.

[14] Raska, P. \& Ulrych, Z.; 2012; Simulation Optimization in Manufacturing Systems; Annals of DAAAM for 2012 $\&$ Proceedings of the 23rd International DAAAM Symposium, ISBN 978-3-901509-91-9, ISSN 2304-1382, pp 0221 - 0224, Editor B[ranko] Katalinic, Published by DAAAM International, Vienna, Austria.

[15] Egri, A. \& Sirb, V. - C.; Smart Control Software for Industrial Process; 2012; Annals of DAAAM for 2012 \& Proceedings of the 23rd International DAAAM Symposium, ISBN 978-3-901509-91-9, ISSN 2304-1382, pp 0517 - 0520, Editor B[ranko] Katalinic, Published by DAAAM International, Vienna, Austria,

[16] Mateia, N. A. \& Cechin - Crista, P.; 2012; Aspects of Multidimensional Optimization; Annals of DAAAM for 2012 \& Proceedings of the 23rd International DAAAM Symposium, ISBN 978-3-901509-91-9, ISSN 2304-1382, pp 0757 - 0760, Editor B[ranko] Katalinic, Published by DAAAM International, Vienna, Austria.

[17] Davies J.; 1979; Induction Heating Handbook; Ed. McGraw-Hill, Londra, UK.

[18] Stefano Menotti, Hans Nørgaard Hansen, Giuliano Bissacco, Patrick Guerrier, Peter Torben Tang; Comparison of two setups for induction heating in injection molding, , The International Journal of Advanced Manufacturing Technology, Volume 81, Issue 9, pp 1863-1870, ISSN: 0268-3768 (Print) 1433-3015 (Online)

[19] Guerrier, P.; Nielsen, K.K.; Hattel, J.H.; 2015; Temperature Dependence and Magnetic Properties of Injection Molding Tool Materials Used in Induction Heating; IEEE TRANSACTIONS ON MAGNETICS, vol.51, no.9, pp.1-7, Sept. 2015, ISSN 0018-9464. 
[20] Balotă Doru Andrei; 2012; Monitoring of Temperature Field in the Injection Mould Heated by Electromagnetic Induction, PhD Thesis, Politehnica University of Bucharest.

[21] Nita, Alexandra, Oanta E.; 2010; Multidisciplinary studies regarding the residual stress minimization in polymeric injected parts, Review Plastics, No.3, pp. 397-401; ISSN 0025-5289.

[22] Raicu Alexandra, Racu Gabriel; 2011; Impact of the development of the polymeric material adviser program to a mold injection encyclopedia; 7 th International Conference on Management of Technological Changes, Management of Technological Changes, Book 1, Alexandroupolis, Greece, pp. 601-604, ISBN: 978-960-99486-23 